\title{
Evolutionary Metaphors for Understanding WAC/WID
}

\author{
Laura Brady \\ West Virginia University, laura.brady@mail.wvu.edu
}

Follow this and additional works at: https://researchrepository.wvu.edu/faculty_publications

Part of the English Language and Literature Commons

\section{Digital Commons Citation}

Brady, Laura, "Evolutionary Metaphors for Understanding WAC/WID" (2013). Faculty Scholarship. 1212. https://researchrepository.wvu.edu/faculty_publications/1212

This Article is brought to you for free and open access by The Research Repository @ WVU. It has been accepted for inclusion in Faculty Scholarship by an authorized administrator of The Research Repository @ WVU. For more information, please contact ian.harmon@mail.wvu.edu. 


\title{
Evolutionary Metaphors for Understanding WAC/WID
}

\author{
LAURA BRADY
}

IN THE RECENT AND IMPORTANT ESSAY, "A Taxonomy of Writing Across the Curriculum Programs: Evolving to Serve Broader Agendas," William Condon and Carol Rutz identify four types of programs: Foundational WAC, Established WAC, Integrated WAC, and WAC as Institutional Change Agent. These programs can be identified by key characteristics such as their primary goals, their funding, their structure or organization, and signs of their integration or success (362-63). To show how this valuable taxonomy works in practice, Condon and Rutz draw on concepts of location and momentum derived from quantum mechanics that they hope will "allow those within a program to gain a sense of place (of where they are, programmatically, in the universe of WAC programs) and a sense of movement (of what steps are available next, and of which might be desirable)" (360-61). When Condon and Rutz shift their taxonomy from static to dynamic description, they shift from a life sciences frame (biological taxonomies) to a physical sciences frame (quantum mechanics). There are distinct advantages, however, to be gained by extending the biology frame. Evolutionary metaphors for understanding WAC/WID complement rich description with dynamic causal analysis of a program's origins, adaptations, and threats; they allow us to consider location, movement, and other factors simultaneously.

This essay extends the evolutionary metaphor to two very different but very successful WAC programs (one at a small liberal arts college and one at a large public university) to show how we might develop and apply a heuristic that can help us explore the evolutionary potential of our WAC programs. That is, if Condon and Rutz's taxonomy helps programs situate and assess themselves in a national context and provides descriptive language that is easily understood by others outside of our field $(379,361)$, then an evolutionary metaphor can provide a useful means of 
internal study: a way of understanding the causes and conditions for a WAC program's origins and reproduction, mutations and adaptations, endangerment, or extinction.

Moving from taxonomy to evolutionary theory follows a historical pattern. Evolutionary theory represented the next scientific step beyond taxonomy for advancing our understanding of the natural world. Carl Linnaeus (Carl von Linné), author of Systema Naturae, 1735, is credited with establishing hierarchical structures for classifying organisms according to their physical traits and their methods of reproduction. His taxonomy relied on visible, observable characteristics. In the late eighteenth century, Cuvier's functional taxonomy superseded Linnaeus's descriptive taxonomy (Foucault 268). In contrast to the externally visible traits emphasized in Linnaeus's taxonomy, Cuvier was beginning to theorize internal causes and conditions that could account for differences and disruptions. "From Cuvier forward," Foucault argues, "it is life in its non-perceptible purely functional aspect that provides the basis for the exterior possibility of a classification" (268). Classification is still useful for Cuvier, but he shifts the categories from highly specific traits to very general principles. In his emphasis on function, Cuvier thus helps lay the ground for Charles Darwin's theory that species formation depends on the natural selection of traits that help an organism adapt to its environment and reproduce successfully. ${ }^{1}$

Darwin's theory of natural selection relies on environmental conditions, mutations, and change. His famous finches adapted to different environmental niches on the Galapagos, with the most relevant factor being the type of available food. In a different place, adaptive coloration may have led Darwin to study predatory/prey relationships. The point remains: if a particular mutation lines up with an environmental niche and gives an organism a reproductive advantage in terms of a food source, protective coloration, or something else it can productively exploit, that trait gets passed along to subsequent generations and eventually a new species is formed. WAC also speciates by adapting to its local environment. Evolutionary metaphors help explain and explore patterns, interrelationships, and the conditions under which a program can thrive. The metaphor can also help us understand that not all mutations are adaptive or successful, and that certain conditions threaten a program's survival.

Evolutionary and ecological metaphors are, of course, not new to WAC discussions or to more general discussions of writing practices. In 1986, Marilyn Cooper argued for "The Ecology of Writing," where writers are part of a varied and inherently dynamic system. Rather than paying attention to individual writers and their immediate contexts, Cooper asks us to attend to the ways in which, "all the characteristics of any individual writer or piece of writing both determine and are determined by the characteristics of all the other writers and writings in the system" (368). For Cooper, contextual models serve a taxonomic function; she notes, for instance, 
that Kenneth Burke's pentad in the Grammar of Motives remains valuable for the ways in which it helps label and describe elements of a writing situation but also remains limited because it fails to explain causal relationships (368). Cooper's ecological model asks questions about behaviors and environments, looks for factors that can promote or prevent writing, and analyzes situations and systems to explain or predict change. These are all helpful strategies for evolving WAC programs.

Sidney Dobrin and Christian Weisser (2002) extend Cooper's dynamic model of interlocking systems, particularly in terms of how groups and species shape and are shaped by their surrounding ecosystem and available resources. "Much like the finches and tortoises in Darwin's theory of evolution," they argue, "writers enter into particular environments with a certain ideological code and then contend with their environments as best those codes allow. These environments have material, social, and ideological qualities" (576). As we examine the effects of local environments on writers and writing, Dobrin and Weisser note that the metaphors we use to describe the writing spaces are important (577). Evolutionary metaphors often rely on the image of a radiating network or web. Cooper uses the image to remind us that "anything that affects one strand of the web vibrates through the whole"(370). Dobrin and Weisser also describe "the webbed writing environment" (585) as they focus our attention on activities as well as locations and on the complex ways in which our physical and social environments shape and are shaped by our writing (578).

Cooper, Dobrin, and Weisser focus on writers and texts. I suggest that we extend their theorization of writers as species to theorize WAC programs (administrative units within specific university environments) as species that similarly evolve, adapt, and reproduce. Martha Patton has already begun this work in her insightful book, Writing in the Research University: A Darwinian Study of WID with Cases from Civil Engineering (2011). In making a case for an evolutionary theory of WID, Patton is quick to note the limitations of any analogy between biological and cultural processes, but emphasizes its value for "discussion of writing in larger forums of competition (not just within, but also beyond the walls of various disciplines)" and as a way "to explore both variability and stability in writing activity, to consider the impact of environment and its varying constraints on writing activity, and to describe the spectacular radiation of disciplinary specializations" (7). Patton's book-length study articulates and illustrates a descriptive theory that encompasses research, teaching, and administration as she analyzes cases from civil engineering. My aims are different: I want to focus on ways in which evolutionary theory can help us create and apply a heuristic for WAC program administration and self-study. 


\section{An Evolutionary Heuristic for WAC Administration and Self-Study}

Darwin points to the heuristic value of his work as he concludes On the Origin of Species. Starting with the premise that every "production of nature" has a history, Darwin anticipates that: "A grand and almost untrodden field of inquiry will be opened, on the causes and laws of variation, on correlation of growth, on the effects of use and disuse, on the direct action of external conditions, and so forth.... Our classifications will come to be, as far as they can be so made, genealogies" (372). But what questions allow us to study patterns of inheritance, especially in terms of tracing the genealogy of WAC? To what degree can we claim that different species of WAC share common goals for writing, thinking, learning, and knowing even as they adapt to the social, intellectual, and physical elements of their home environments? ${ }^{2}$ And what is the effect of environmental enrichment? Too often, we seem to speak in Lamarckian terms where change is rapid, progressive, easily passed along to offspring, and never resulting in extinction. A Darwinian model suggests that change occurs much more gradually over several generations where successful mutation allows an organism to survive and reproduce while failed mutation results in extinction. As Darwin summarizes, "natural selection... only takes advantage of such variations as arise and are beneficial to each creature under its complex relations of life" (95). We see this in the only illustration in Origin of Species, the "Tree of Life" (see Figure), where Darwin shows branches extending from a common root. On both sides of the diagram, we see that development is not symmetrical. On the right-hand side of the diagram, in particular, we see how some branches become extinct as others form the main trunk (87).

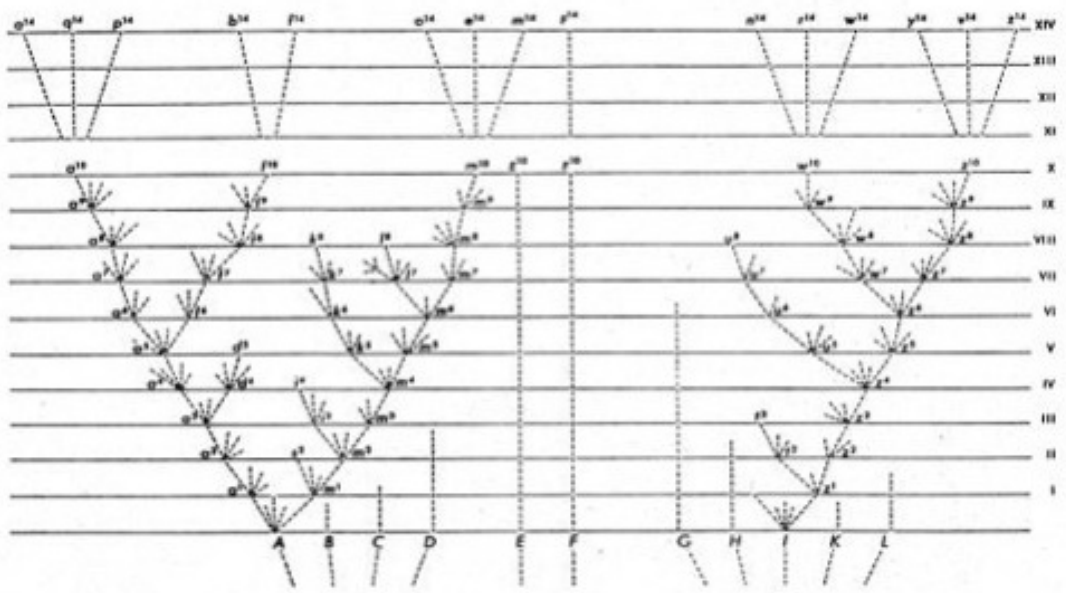

Figure 1 Darwin's Tree of Life illustration, Origin of Species, 1859, p. 87. 
Because of its ability to analyze causes for variation, survival, and extinction in a non-linear manner, Darwinian selection and reproduction is a useful model, yet this evolutionary metaphor (like any metaphor) is necessarily limited. It forces a focus on change and physical environments without directly addressing social interactions, ideologies, and enculturation (a point that Condon and Rutz were perhaps trying to address with their metaphor from quantum mechanics). Nonetheless, the evolutionary metaphor can, if used heuristically, provide a structural and conceptual frame for exploring program history, variation, survival, and extinction. It should let us look for common patterns as well as local variations in ways that might prove particularly useful for new or emergent programs where location and momentum have yet to be established.

Such a heuristic for exploring the genealogy and adaptation of WAC programs might focus on the following questions:

1. What distinctive features define WAC at your site?

2. What strategic alliances establish, support, or advance your program?

3. What conditions initiate, develop, threaten, or sustain WAC at your site?

The first question establishes existing structures. Questions 2 and 3 focus on factors that shape change over time.

In the quick sketches below, I will test this heuristic's ability to explore what is ecologically interesting about an existing program's genealogy (its innovations, replication, and survival; or its innovations, endangerment, and extinction). The places where the evolutionary metaphor inevitably breaks down will, I hope, draw attention to the ways in which programs are also shaped by complex social interactions and ideologies, a point I will come back to in my conclusion.

In other words, I am working from the premise that WAC programs do not spring forth fully formed. Some, for instance, may start as an innovation (or mutation) in a single semester when a member of the writing faculty collaborates with another discipline to present a workshop on writing; others may start with some funds from a seed grant or in response to a university assessment initiative. Whether or not something further evolves from that innovation then depends on whether or not it proved successful and whether or not conditions exist for repeating the activity. Changing conditions always drive the processes of selection and replication, generally with the goal of continuation or survival. If an innovation (such as a WAC initiative) survives, then other changes are likely to follow as the cycle continues. The progression does not, however, follow a straight line. That is, some innovations will prove dead ends, some changes will enrich, and still other changes will respond to a completely distinct set of conditions and start a new branch. With an evolutionary heuristic, we can 
look to long-standing and well-documented WAC programs to trace their genealogies and the adaptive alliances that form along the way.

To test the heuristic for exploring the genealogy and mutation of WAC programs, I am choosing to look at two distinct environments: Carleton College, where the WAC program flourishes within a small liberal arts college setting, and George Mason University, which represents a successful program in the context of a large research university. There are clearly many other long-standing programs that could provide equally compelling cases for study. I am choosing these two for the distinctive ways in which the programs speciated by adapting to assessment requirements (somewhat like looking just at beak adaptations in Darwin's famous finches), and because I was able to augment the richly documented histories of each program (available through existing scholarship and Web-based materials) with site visits where the directors generously allowed me to interview them and see some aspects of their programs in action.

\section{Carleton College: Features, Alliances, and Conditions within a Liberal Arts Environment}

Carleton is a highly ranked, private liberal arts college in Northfield, Minnesota, with about two thousand undergraduate students (90 percent of whom live on campus) and 200 faculty. Admissions are competitive with only 21 percent of applicants accepted in 2013. The school's history dates back to 1866. Among other goals, Carleton "strives to be a collaborative community that encourages curiosity and intellectual adventure of the highest quality" with an academic focus on "developing the critical and creative talents of our students through broad and rigorous studies in the liberal arts disciplines" (About Carleton). The size of Carleton helps foster a strong sense of community where colleagues share a common commitment to the value of a liberal arts education. As Carol Rutz, director of Carleton's Campus Writing Program, explains, "They share a belief that communication skills, variously defined, will help students in every aspect of their lives whether it's advancing their learning as undergraduates or helping them succeed in the next phase of their lives. . ... It's there in physics as much as it is in music or history" (Interview).

Carleton's WAC program is most recently documented in the College Composition and Communication article that I cited in my introduction. In that article, co-authors William Condon and Rutz (director since 1997) trace Carleton's four-decade progression through the various types identified in their taxonomy. They note Carleton's status as a Foundational Program in the 1970s (366); its twenty-year "limbo" as an Established Program (369); the step to becoming a Type 3 Integrated Program around the year 2000 (373); and the effect of a new curriculum in 2010 that establishes WAC at Carleton as an Institutional Change Agent (Type 4) on the basis of its 
role in "assessment of student outcomes at multiple sites" as well as WAC's continuing focus for faculty development (378). In other articles that document Carleton's history, Rutz and her colleagues are able to trace the branching progression in more detail. An analysis of the program's genealogy shows, for instance, how WAC at Carleton has become closely allied with assessment even as it maintains its early elements of faculty and curriculum development.

\section{What Distinctive Features Define WAC at Carleton?}

As I noted above, the aim of this first question is descriptive. Carleton College is now well known for its use of portfolios to assess students' writing abilities and experiences. Approaches to writing and the teaching of writing have, however, evolved over several decades. Faculty development workshops in the mid-1970s initially supported a change in the way in which undergraduates would meet a campus-wide writing requirement. Instead of taking a single composition course taught by the English department, Carleton students could take a course in any subject that had a "Writing Requirement" (or WR) designation. Rutz, Hardy, and Condon trace this history in a 2002 essay in which they observe that, "the system was distinctive in having replaced a system of instruction with one of certification" (9). They explain that the early stages of the WAC program "rested on the assumption that faculty were already assigning a good deal of writing in their courses across the curriculum; workshops that focused on creating and responding to writing assignments then provided faculty outside of English with the support they needed to offer these WR courses" (8-9). Over time, this innovation has become but one aspect of Carleton's multifaceted program. Interestingly, the 2002 essay uses an evolutionary metaphor to describe cycles and conditions of change. That metaphor, adapted as a heuristic, can help explore not only changes over time in a single program but changes that occur across programs.

For instance, cross-disciplinary faculty workshops were successfully replicated at Beaver College. Elaine P. Maimon credits Harriet Sheridan's "faculty rhetoric seminars" at Carleton College in 1974 and 1975 as the inspiration for organizing similar faculty workshops at Beaver College. Writing in 1990, Maimon observes: "Now that such faculty gatherings have become as familiar as committee meetings, we forget that the faculty workshop was something new in the seventies.... [I]t is different in that the workshop is (1) scholarly and pragmatic and (2) politically and intellectually nonhierarchical" (142). It's a good reminder that WAC programs don't emerge fully formed. At Carleton and elsewhere, faculty workshops on the teaching of writing help establish writing as an institutional value that cuts across all disciplines. 


\section{What Strategic Alliances Support or Advance WAC at Carleton?}

Even within Carleton's writing-rich habitat, WAC depends on relationships and partnerships (co-adaptive alliances in terms of evolutionary theory). When I interviewed Carol Rutz about current conditions at Carleton, she continually brought the conversation back to her colleagues across campus. According to Rutz, the faculty are "completely committed. They are what make it all work." Faculty alliances have, in fact, helped the portfolio assessment model not only survive but replicate.

A symbiotic relationship between WAC and Qualitative Reasoning (QR) began "almost accidentally" when a group interested in improving QR instruction thought to look for examples within the writing portfolios that Carleton students already submit on a regular basis. The Quantitative Inquiry, Reasoning, and Knowledge initiative (QuIRK) found that "by placing QR in the context of argument, we can leverage the assets of the writing program to overcome institutional barriers, develop broad faculty support, and sidestep cultural inertia that plagues new initiatives. And, we argue, all of this can be done while reflecting facets of QR that would otherwise be underrepresented in programming" (Grawe and Rutz 16). One of the initial barriers was funding. Darwin would, of course, remind us that organisms compete for limited resources. By partnering with WAC, the program was able to move forward without a budget line while establishing a critical mass of support. Now that the initiative has found grant funding of its own, it can reciprocate by offering support to writing. Beyond shared funding, the two programs can share another limited resource: faculty time (10). This alliance and replication has proven so successful that other cross-curricular initiatives at Carleton continue to extend the model: librarians at Carleton now have an independent research project that uses portfolios to see how students are using sources (Rutz Interview). Rutz summarizes the advantage of these faculty alliances: "What we all share is a genuine respect for students and a genuine commitment to helping students learn. How we enact that just plays out differently in different disciplines" (Interview).

Continuity for any program depends to some degree on budgets and upperadministration decisions. As a result, administrative alliances also have to be fostered and maintained. Rutz notes that she needs to build and rebuild her relationship with the associate dean position since that role rotates every three years. "For many years," she explains, "I met with the associate dean every two weeks and could drop in as needed. Now I meet once a month and their schedules don't allow for informal meetings. It's harder to build relationships." An alliance with upper administrators matters not only in terms of sustaining current work but also in looking to the future of the program since those alliances will almost certainly shape the transitions and continuity in program leadership. When Rutz was initially hired in 1997 (at a key transition point when the program was shifting its focus from faculty workshops 
to an assessment-based model), she was in a temporary position that has gradually grown to full-time over the years.

It is now impossible to imagine Carleton's program achieving or maintaining its current status without the support of a full-time director. (The position is currently defined as two-thirds administrative and one-third adjunct teaching.) Rutz notes, however, that while the position is now full-time, it remains limited in at least two ways. Because the position is not tenure-track and is not allied with any department, it is not protected in the same way as a tenured faculty position, which could prove a threat to the position's (and the program's) long-term survival. While the position emphasizes the College Writing Program director's active role as a teacher and thus contributes directly to Rutz's credibility with faculty colleagues, she points out that the position has limited opportunities for curricular involvement or development. The departmental home for the director could, from her perspective, "be Physics as easily as English," but it would give the position "a constituency other than the dean's office" (Interview).

While Carleton's program will certainly continue to thrive as long as Rutz directs it (thanks in no small part to her deep history with and knowledge of the campus culture in addition to her knowledge of and contributions to WAC scholarship), she voices some concerns when asked about how she might manage transitions and continuity in leadership at some future point:

I don't think it's up to me. . . My big worry is that cold-hearted administrators facing budget pressures could look at my position and decide that they could get it all covered without replacing me: my teaching could be absorbed by a department, my portfolio work could be absorbed by the assessment office, and my faculty development work could be absorbed by the Center for Teaching and Learning. While the College could get it all covered that way, there would be no leadership model, and-as Ed White has said-having no leadership is risky. There would be no one to pay attention, to do the tending.

Also, finding replacements depends on where you are. Does Carleton know what to look for? ... Will Carleton have the choices that a place with more visibility or a different location will have? I don't know. (Interview).

Rutz's concern about the future of WAC at Carleton is a concern that may resonate with many directors: despite any program's strong grassroots support, its future may still be determined by budgetary and administrative factors, with decisions made by colleagues who do not have scholarly knowledge of our field.

Studying Carleton's past and present program through an evolutionary lens demonstrates ways in which even the strongest and most well-established programs must 
continually have someone "to pay attention, to do the tending," to adapt to changing conditions, compete for limited resources, and establish alliances and niches. In addition to needing someone to "do the tending," that someone can't just be anyone. The position requires more than a simple interest in writing; it also requires professional expertise and knowledge of existing scholarship. That is to say, the position of director has become a key feature of WAC as a species. At the risk of stretching the metaphor to the breaking point, directors are a key feature for WAC in somewhat the same way that eyes are a key feature for vertebrates. If WAC were to mutate and become director-less, there is a strong chance that WAC as a species would not only lose programmatic vision but would become extinct (or, barring extinction, WAC might be forced to adapt to a dark and low-energy environment like the eyeless fish in Mammoth Cave).

\section{What Conditions Develop or Sustain WAC at Carleton?}

The WAC program at Carleton can now claim a 40-year history. Since long-term change is rarely linear, the innovative workshops that proved to be so important to establishing writing as a core value were not enough to sustain the program without some structural changes. Rutz, Hardy, and Condon cite consistency as the largest challenge (10). They explain that a 1996 internal report on writing revealed that student and faculty experiences within the Writing Requirement courses varied widely. Students noted disparities about the number and length of papers and revisions; faculty noted difficulties in evaluating content versus writing and questioned whether they looked for the same writing skills as their colleagues (10). Because so many faculty were certifying writing requirements in the absence of any common criteria, the certification process also lacked consistency. To adapt to these challenges, Carleton shifted from a faculty-centered approach to one that put students' own writing (and writing selections) at the center. The result: a mid-career portfolio assessment (12). The mutation established a new link between instruction and assessment. Portfolio assessment is now not only established, but starting to replicate in other contexts. In the meantime, faculty development workshops continue to play an important but slightly different role in sustaining campus-wide values.

Rutz and Lauer-Glebov discuss the ways in which one change brings about other shifts in their article, "Assessment and Innovation: One Darn Thing Leads to Another." In particular, they note "a marked change in faculty culture" where instructors take a much more collaborative approach to writing instruction now that "portfolio scoring sessions and other faculty development activities foster continued conversations about students, teaching, and learning" (90). They also point out that the culture is supported with some material resources: "Incentives in the 
form of stipends, course development grants, and abundant good food have helped strengthen and maintain participation" (90).

While resources do not have to be enormous, they are crucial to a program's survival: they signal that WAC has an established niche. An infusion of funding, for instance, can accelerate change, but there must also be some ongoing support. For instance, initial grant funding at Carleton in 1999 helped create focus and deadlines; the ability to bring highly visible scholars to campus helped forge alliances, gain a national perspective, and spark conversations across campus (Rutz interview). Likewise, steady support such as the continuing appointment of a WAC director and regular funds for faculty development workshops have helped sustain changes over time. As an "institutional change agent" (Type 4 in Condon and Rutz's taxonomy), Carleton's current program may seem fairly secure, but there remains the risk of being subsumed by other innovations. "Writing is assumed as a learning vehicle; it's part of the culture," explains Rutz. "It works so well that it's almost reflex." If anything, the challenge now is to keep faculty aware of the role that writing plays in their teaching so that writing does not become invisible, "like fluoride in the water." The administration at Carleton recently directed a modest bequest to support writing assessment; that decision helps keep the program visible and helps fund its longterm survival (Rutz interview).

WAC speciates by adapting to its local environment; assessment is, for most schools, an environmental requirement. Some species of WAC are better at adapting than others. At Carleton, the portfolios represent a mutation that allowed Carleton to speciate from the proto-species of college writing in general. Co-adaptive alliances emerge as one of the most relevant factors for sustained existence. To explore the ways in which the specific alliances depend on very local conditions, I want to test the heuristic value of the evolutionary metaphor a bit further, first by applying it to a very different institutional context.

\section{George Mason University: Features, Alliances, and Conditions within a Research University Environment}

Like Carleton, the WAC program at George Mason University dates back to the seventies. Like Carleton, assessment has come to be an increasingly central aspect of WAC. Like Carleton, Mason's assessment plan is featured on the WPA Assessment Gallery.

Like Carleton, the US News and World Report has rated Mason as a top program for writing in the disciplines. ${ }^{3}$ Unlike Carleton, George Mason is a large public research university.

The institutional environment at Mason has changed rapidly over five decades. In 1966, Mason was a four-year college with fewer than a thousand students; by 
1972, it was an independent university with 4,000 students. By the late seventies (as WAC was getting established), enrollment had already climbed to 10,000. Over the next fifteen years, the size more than doubled to 24,000 by 1996 . It is now a major teaching and research university (named the top national university to watch by US News \& World Report in 2008) with 33,000 students and roughly 1,800 faculty across almost 200 degree programs on three campuses. Due in part to its location in the Washington D.C. metropolitan area of northern Virginia, George Mason University is also characterized by diverse cultures and communities, and 38 percent of its students attend part-time (About Mason).

\section{What Distinctive Features Define WAC at George Mason University?}

George Mason University's motto is revealing: "Where Innovation is Tradition" (About Mason). When Mason's WAC program was featured in Fulwiler and Young's 1990 collection Programs That Work, Chris Thaiss began his contribution with the simple assertion, "George Mason grows" (223). Thaiss, who directed the WAC program from its beginnings through 1998, witnessed changes in enrollment, staffing, curriculum, and institutional mission. In this institutional context, program survival has relied on continuous adaptation and innovative responses to state mandates and other changing conditions (such as shifts in state allocations of resources). In evolutionary terms, innovation is the key to survival. The WAC program has learned to balance innovation with stability in interesting ways.

The first cross-disciplinary efforts at Mason were (like Carleton's) tied to faculty workshops. The voluntary workshops, held on a weekend, began with some minimal funding from the dean's office. In his 1990 article, Thaiss credits the WAC program's "second major boost" to two state-supported grants: one focused on pedagogy, which allowed the weekend retreats to grow into a five-week institute; the other focused on research and led to a conference and a collection of essays on WAC published in 1983 (224). These twin strands of teaching and publication reflected the shifting institutional climate as Mason worked to establish itself as a serious research university. A third stage quickly followed: a redesign of the English composition requirement in 1983 moved the second required writing course to the junior year with the creation of meta-disciplinary courses that focused on writing in the Humanities, Social Sciences, and Natural Sciences/Technology; a fourth emphasis on writing in business contexts was added in 1986. This emphasis on writing in the disciplines was followed with the Faculty Senate's approval of an additional writing-intensive requirement in the major in the early 1990s accompanied by the creation of a WAC committee (Zawacki interview).

Terry Zawacki succeeded Thaiss as WAC director in 1998. Almost forty years after the earliest WAC initiatives at Mason, faculty workshops, researched publications, 
and significant writing throughout a student's undergraduate career remain central to the program. In particular, the upper division composition requirement that focuses on four broad meta-disciplines has had an important role at Mason. It puts students from different disciplines together so they can see differences within, between, and outside their own majors (an insight developed in Thaiss and Zawacki's Engaged Writers). While environmental conditions at Mason do not support portfolios as Carleton's environment does, these upper division courses serve a similar structural role as a site for assessment (a point I will say more about in a moment).

When asked to highlight the most distinctive features of the WAC program as it exists at Mason today, Zawacki, director from 1998 to 2013, notes "the longevity of the program and the culture of writing it has established." The well-established culture of writing at Mason, she explains, "depends on a large network of relationships" to sustain WAC over time and through changes at the department, college, and university level.

\section{What Strategic Alliances Support or Advance WAC at Mason?}

Strong co-adaptive alliances between WAC and other initiatives (such as assessment, national and international research collaboration, or community outreach) can help us understand not only how George Mason University created institutional change, but also why the program is shaped by its specific environmental conditions. The specific institutional conditions at Mason have shaped writing in ways that suggest that WAC does speciate and diverge from common roots as programs develop features that respond to their local environment.

For instance, assessment is a key strategic alliance for many WAC programs. At Mason, however, assessment of written communication is also a state mandate.

The state mandate represents an environmental requirement that posed both an opportunity and a threat for WAC. On the one hand, it held the potential to strengthen teaching and learning. On the other hand, the state's preference for standardized testing threatened to overlook many important local and contextual factors. Fortunately, writing assessment at Mason had a strong ally in Karen Gentemann, Associate Provost for Institutional Effectiveness. Zawacki credits Gentemann with supporting the writing assessment plan that Mason developed ${ }^{4}$ and arguing for it at the state level.

Mason's existing writing-intensive requirement made it possible to keep writing assessment tied directly to courses rather than depending on tests outside the classroom as the state initially proposed. Both the Writing Across the Curriculum Committee and the Writing Assessment Group, a cross-disciplinary committee of experienced WAC faculty convened by Gentemann, worked together to assess the effectiveness of WAC efforts through departmental reviews of randomly selected 
papers written in response to a representative assignment in upper-division writingintensive courses and assessed with a discipline-specific rubric. These sample papers were augmented with surveys of faculty and undergraduates. The combined results of this multi-strand embedded assessment process continue to inform ongoing curriculum and faculty development work and the Office of Institutional Assessment has become the main venue for department-level faculty development workshops. This strategic alliance between WAC and assessment is detailed in Zawacki and Gentemann's essay, "Merging a Culture of Writing with a Culture of Assessment: Embedded, Discipline-based Writing Assessment."

This strong assessment model, in place since 2002, faced a new challenge when the Virginia State Council of Higher Education (SCHEV) revised its competency-based guidelines to require institutions to conduct "value-added" assessment (Zawacki et $a l)$. To be sure that the new state guidelines did not impose timed writing tests or other measures that Mason had already rejected as unproductive, the WAC program needed to defend its successful course-embedded processes for assessing writing over time and in varied contexts; it needed to demonstrate that "writing instruction itself was adding value to students' overall educational experience" (Zawacki et al). Again, co-adaptive alliances played a key role in bringing first-year composition (FYC) into the established upper-division WID-based writing assessment process while being mindful of how to make the process productive for FYC curriculum and faculty development.

E. Shelley Reid, the director of first-year composition at George Mason, was able to embed a pre-assessment in the FYC course that considered student writing in the context of upper-division composition courses as well as WID courses. That is, how prepared were students to take advanced writing courses? Reid and her colleagues collaboratively created a rubric that considered several traits according to levels of competency, emerging competency, and consistency. They applied the rubric to 153 randomly selected samples of a single researched essay - a sample that represented roughly ten percent of the FYC student writers (Zawacki et al.). The process allowed Reid and her colleagues to consider FYC not only in terms of how it develops students' writing but also in terms of how it prepares them for future writing tasks. Their discussions raised questions about what skills can or should transfer and why transferability is such a complex issue. Reid's discussions resonated with similar conversations that Zawacki had with WID faculty.

For Zawacki, the fact that the majority of the FYC papers in the course-embedded assessment received "emerging competence" as their final score adds quantitative evidence "that all teachers must take responsibility for helping students develop into fully competent writers in their courses, whether in or outside of the major." In addition to these implications for helping students succeed as college writers, the 
cross-disciplinary assessment process was also important in building and sustaining collaborations and conversations about larger university writing cultures (Zawacki, et al.).

\section{What Conditions Develop or Sustain WAC at Mason?}

Survival for any WAC program depends on successful competition for key resources: money, people, and time. Like Carleton, Mason has established itself over decades of work and generations of change.

In terms of funding, Mason's program initially relied on year-to-year allocations from the dean's office and then a series of state grants. It was not until 2001 that the program was given a line item budget from the Provost's office to cover the WAC director's position and workshop stipends. The addition of two graduate research positions in 2005 further expanded and stabilized the budget. The provost recently promised a full-time assistant director (expanding the position from a part-time role), and future plans include a designated space for WAC. As Condon and Rutz note, "substantial, permanent institutional funding for well-defined and established roles and personnel" is one clear sign of a program's institutional importance (362).

Time is a more problematic condition in many ways. One of the George Mason University's institutional goals is to move from being a High Research Activity University to a Very High Research Activity University according to Carnegie standards. That institutional focus can cause a shift in what faculty perceive as valuable. Research universities typically do not reward teaching in the same way they recognize and promote publication and scholarship. WAC director Terry Zawacki explains how this has an effect on WAC: "Many [research faculty] do not want to teach writing intensive courses because they are labor intensive. As a result, we are seeing an increase in the number of adjuncts and term-appointment teaching faculty who are assigned to writing-intensive courses, although the original intent was to have those classes taught by full-time faculty." At the same time that the program is seeing fewer research faculty willing to commit their time to teaching initiatives, the WAC director's research expectations are also increasing: "National ranking depends on external work - publishing, being involved with the Clearinghouse, and so forth. For instance, the fact that George Mason University has been recognized for the past ten years in the US News and World Report rankings has helped establish visibility and credibility for our programs in important ways, but it also creates pressure to maintain that ranking" (Zawacki interview). How does a director balance the need to build internal relationships and networks with the pressures to publish? The director's role is, as noted in the discussion of Carleton's program, a key feature of the many species of WAC in various environments. 
Another condition for program sustainability depends on planning for continuity. Zawacki poses the question, "How do you value and preserve important institutional history when the initial transition plans didn't work out?" Mason intended to hire their next WAC director while the existing director (Zawacki) was around to provide some introduction and context. That year of overlapping roles proved impossible when the search for a new director took longer than planned. While the program now looks forward to their new director's ideas and initiatives, some institutional history will inevitably be lost despite attempts to create a rich internal archive to augment the ways in which publications already document the program's evolution. Zawacki suggests that all programs consider how to strike a balance between history and innovation. Tracing and preserving a genealogy can help. ${ }^{5}$

\section{Conclusion}

An evolutionary heuristic identifies common patterns while also exploring the causes for local variations. It attends to conditions that support or threaten continued survival. By focusing on change and institutional environments without directly addressing social interactions, ideologies, and enculturation, however, the evolutionary metaphor risks placing WAC program directors in a reactive role when what they need is a proactive role that allows them to initiate change and prevent threats.

That is, the evolutionary metaphor breaks down at a crucial point: there is no intentionality in Darwin's theory. (Polar bears cannot secure their survival in the face of global warming by deciding they need a new way to hunt for food or a new food source.) If I keep extending the metaphor, I suppose I could argue for artificial evolution where humans have recently tried to insert intentionality via genetic mutations (such as gene splicing, recombinant DNA, and so forth). But even this example of intentionality only goes so far. No one can fully predict how an artificially designed mutation will survive and interact within a real environment (i.e., whether it will produce a positive effect such as the prevention of genetic diseases or a negative effect such as antibiotic resistance).

While WAC directors certainly have intentionality and agency, that agency is always and necessarily limited. What happens, for instance, when a new dean or provost no longer supports an existing WAC program? Or when the institutional emphasis on research prompts faculty to withdraw from teaching writing-intensive courses because that work is perceived as less valuable than their publications? Or when students do not see the connections between disciplinary writing and knowing? Competing needs and goals further complicate evolutionary theory. We need to take complex social interactions and ideologies into account to understand the complex history of a program and its potential transformations. 
Acting on the premise that complex human interactions can be studied much like any other organism, biologist David Sloan Wilson proposes a theory of cultural evolution that might help us answer questions about agency and competing goals. In The Neighborhood Project, Wilson uses examples from biology as "parables" to illustrate successful niche adaptation and poisonous competition (insects that walk on water called "striders") as well as effective collective action (the organization of wasp colonies). He follows these parables with examples of how he and a host of collaborators are beginning to map and study similar processes of adaptation, competition, and collective action in the urban environment of Binghamton, New York. He notes that evolution is "fundamentally about change" and results in a "full spectrum of outcomes" (11). Specifically, he hopes to identify and avoid the conditions that produce individuals who "benefit themselves at the expense of their neighbors" (the striders in his parable) and, instead, identify and promote the conditions that produce individuals who "behave for the good of their groups" (more like wasps) and thus represent "the essence of solid-citizenry" (77). By studying and managing conditions, Wilson contends, the world (or at least his corner of it) can become a better, more cooperative, and harmonious place. The resulting theory of cultural evolution and its goal of producing positive, collective, social action is ambitious and optimistic and yet to be fully proved (the Binghamton project is largely still at the data-gathering stage with only initial, isolated results). Still, Wilson's use of evolutionary science to foster groups that can solve real-world problems shows the analytic value of extending the theory to complex social interactions.

A close study of successful WAC adaptations and evolutions can similarly provide instructive stories to help us examine our own environments with new eyes, attending particularly to ways that our local programs might fill a particular niche or address a particular need through campus-wide collaboration. The evolutionary heuristic that I suggested at the start of this essay works to trace and preserve a program's genealogy, its growth, and its changes over time. It can also provide a way of evaluating where a program wants to go. Close study of both Carleton College and George Mason University's programs specifically identified assessment as an environmental requirement to which each WAC program had to adapt, but also affirmed the importance of a strong and professionally knowledgeable director to build and sustain campus-wide collaborations. As the director of a slowly emerging WAC program, these cases (which were part of a larger, year-long study of several different programs) helped me understand the environmental niche that WAC may and may not fill at my home institution, specifically by looking at available alliances and existing conditions. The initial heuristic has led to more specific questions that 
my colleagues and I are starting to address as we identify existing strengths and challenges as well as our needs and goals.

Here is an expanded version of the evolutionary heuristic that others may find helpful as they trace the past, describe the present, and look to the future:

1. What distinctive features define WAC at our site? Where is writing already happening? What do we know about how faculty and students use writing to develop disciplinary knowledge? How do we gain that context? How can we assess whether or not writing develops disciplinary knowledge?

2. What strategic alliances establish, support, or advance our program? Where do alliances already exist? What can we do to sustain them? Where should WAC be located to foster new alliances? What do different disciplines identify as their writing needs and goals? How can a partnership with WAC help advance those goals? What is the benefit of a WAC partnership?

3. What conditions initiate, develop, threaten, or sustain WAC at our site? Can department-based efforts make a campus-wide difference? Who and what connects WAC efforts across campus? Who is involved? How are the short- and long-term goals decided? Is the process inclusive and consensus-oriented (rather than top-down)? What happens when new administrators introduce new priorities? Or when initial resources (such as development funds) are exhausted? What might celebrate and sustain successful efforts?

The WAC initiative at my university is still very new. We are, like Wilson's Binghamton Neighborhood Project, still at a data-gathering stage and still building alliances as we try to create a successful, cooperative WAC model. Looking closely at existing programs (through site visits, interviews, and publications) was one step in the process. Successful WAC collaborations from one school can never be replicated at another school because of variations in local conditions, but studying existing models through an evolutionary lens did reveal similarities and differences that helped refine our questions for self-study and planning.

A cultural theory of evolution of the sort that Wilson describes is particularly helpful for considering any project that depends, as WAC generally does, on largescale collaboration. Unlike social Darwinism's emphasis on competition, individualism, and "survival of the fittest" Wilson's theory focuses on group selection and collective action. In fact, Wilson's "parable of the strider" cautions against selfish behavior while his "parable of the wasp" (and the "parable of the immune system" later in the book) clearly favors cooperation. Perhaps Wilson's model also appeals because it implies that prosocial group organisms can control or manage the evolutionary process. I suspect that Wilson's reliance on group selection may remain controversial 
among evolutionary biologists because of the implied agency, but metaphorically it's a valuable addition: it allows for a proactive role that allows WAC programs to initiate change and to anticipate and mitigate threats (even if we cannot always prevent them). A WAC program might just secure its survival in the face of budget cuts and shifting priorities by the collective actions of small groups of faculty and students across campus who, connected by well-defined goals and strategic alliances, form symbiotic relationships to practice writing in ways that contribute to their own disciplinary knowledge and to the larger campus-wide culture of writing. In the most optimistic extension of the metaphor, WAC programs become catalysts for accelerating positive educational changes-the very "Institutional Change Agents" that Condon and Rutz celebrate as the most evolved type of program in the taxonomy that inspired this essay.

\section{Notes}

I would like to acknowledge the generous colleagues who helped this essay evolve, especially Roy Andrews, Carol Rutz, Tom Sura, Tim Sweet, Terry Zawacki, and the WAC Journal reviewers.

1. Cuvier did not believe in evolution. He believed that function alone determined existence and that organisms remained unchanged until a catastrophe caused extinction and the development of a new species. His catastrophe theory seems particularly unhelpful in considering WAC programs.

2. Terry Zawacki and Michelle Cox compile a list of commonly held goals and principles in their work on L2 writers and WAC. See their introduction to the forthcoming collection, WAC and Second Language Writers: Research towards Linguistically and Culturally Inclusive Programs and Practices (the WAC Clearinghouse and Parlor Press, 2014).

3. The rating is a result of a strong, existing program in terms of curriculum, faculty, staff, and students, but it is also the result of visibility through local and professional networking as well as national and international scholarship. Only 21 schools nationally make that list; 12 of the schools are public institutions ("Writing in the Disciplines," US News 2013).

4. The writing assessment narrative for George Mason University is available online at the WPA Assessment Gallery http://wpacouncil.org/GeorgeMason. It is interesting to compare it to Carleton's narrative, which is also featured as a model: http://wpacouncil.org/CarletonColl. As the head note to each narrative explains: "Together, the White Paper and assessment models illustrate that good assessment [models] reflect research-based principles rooted in the discipline, is locally determined, and is used to improve teaching and learning" (emphasis added).

5. Tracing the genealogy of WAC at Mason makes it easy to see why its clear identity, its interdisciplinary policies, and its range of stakeholders would make it a useful example of an established program in Condon and Rutz's taxonomy (Type 2), but it is equally easy to see 
how Mason demonstrates their larger point that the taxonomic categories are not mutually exclusive (379). The established structures and supports at Mason, the upper administration's recognition of WAC assessment practices, and writing infused curriculum are typical of Type 2 (Integrated) programs. Mason also possesses the traits of a Type 4 program where WAC is driving change, where the program has substantial permanent funding, where each department is engaged, where WAC is a signature program for the institution and fully theorized, and where multiple campus initiatives coming together to create and sustain a culture of writing (Condon and Rutz 362-63, 274-76). But there is a cyclic, non-linear progression at play, too. The institutional emphasis on research may find Mason once again working to persuade colleagues across campus that writing is everyone's responsibility (Type 1).

\section{Works Cited}

“About Carleton." Carleton College. Carleton College, 2013. Web. 5 July 2013.

“About Mason." George Mason University. George Mason University, 2013. Web. 8 July 2013.

Condon, William and Carol Rutz. "A Taxonomy of Writing Across the Curriculum Programs:

Evolving to Serve Broader Agendas." College Composition and Communication 64.2 (Dec. 2012): 357-82. Print.

Cooper, Marilyn M. “The Ecology of Writing.” College English 48.4 (April 1986): 364-75. Print. Cuvier, Georges Baron. The Animal Kingdom Arranged After Its Organization: Forming a Natural History of Animals, and an Introduction to Comparative Anatomy. Trans. and ed. Edward Griffiths et al. London: G.B. Whittaker, 1827. Internet Archive. Web. 4 March 2013.

Darwin, Charles. On the Origin of Species (1859) and The Descent of Man (1871). New York: The Modern Library, 1936. Print.

Dobrin, Sidney I. and Christian Weisser. "Breaking Ground in Ecocomposition: Exploring Relationships between Discourse and Environment." College English 64.5 (May 2002): 566-89. Print.

Foucault, Michel. The Order of Things: An Archeology of the Human Sciences. New York: Random House, 1970. Print.

Fulwiler, Toby, and Art Young, eds. Programs That Work: Models and Methods for Writing across Curriculum. Portsmouth: Boynton/Cook, 1990. Print.

Gladstein, Jill M., and Dara Rossman Regaignon. Writing Program Administration at Small Liberal Arts Colleges. Anderson, SC: Parlor Press, 2012.

Grawe, Nathan, and Carol Rutz. "Integrating Quantitative Reasoning Initiatives with Writing Programs: A Strategy for Effective Program Development.” Numeracy 2.2 (2009): 1-18. Web.

Linné, Carl von. A General System of Nature, through the Three Grand Kingdoms of Animals, Vegetables, and Minerals. 1735. Trans. William Turton. London: Lackington, Allen, and Company, 1802. Internet Archive. Web. 4 March 2013. 
Maimon, Elaine P. "Beaver College: Getting the Conversation Started." Fulwiler and Young 138-46.

Patton, Martha Davis. Writing in the Research University: A Darwinian Study of WID with Cases from Civil Engineering. Cresskill, NJ: Hampton Press, 2011. Print.

Rutz, Carol. Director of the College Writing Program, Carleton College. Personal interview. 8 May 2012.

Rutz, Carol, Clara Hardy, and William Condon. "WAC for the Long Haul: A Tale of Hope." WAC Journal 13 (Fall 2002): 7-16. Print.

Rutz, Carol, and Jacqulyn Lauer-Glebov. "Assessment and Innovation: One Darn Thing Leads to Another." Assessing Writing 10.2 (2005): 80-99. Print.

- Carleton Writing Program. Carleton College, 2013. Web. 1 May 2013. <http://apps.carleton. edu/campus/writingprogram/>.

Thaiss, Chris. "George Mason University: Introduction.” Fulwiler and Young 221-28.

Thaiss, Chris, and Terry Myers Zawacki. Engaged Writers and Dynamic Disciplines: Research on the Academic Writing Life. Portsmouth: Boynton, 2006. Print.

Wilson, David Sloan. The Neighborhood Project: Using Evolution to Improve My City, One Block at a Time. Kindle Edition. New York, Boston, and London: Little, Brown and Company, 2011. E-book. 28 August 2013.

"Writing in the Disciplines." College Ranking Lists. US News and World Report, 2013. Web. 28 February 2013.

WPA Assessment Gallery: Assessment Models. The Council of Writing Program Administrators (WPA) and the National Council of Teachers of English (NCTE). 2010. Web. 20 March 2013.

Zawacki, Terry Myers. Writing Across the Curriculum (WAC) Program Director. George Mason University. Personal interview. 16 April 2012.

Zawacki, Terry Myers, and Michelle Cox, eds. "Introduction." WAC and Second Language Writers: Research Toward Linguistically and Culturally Inclusive Programs and Practices. The WAC Clearinghouse and Parlor Press. Forthcoming, 2014.

Zawacki, Terry Myers, and Karen M. Gentemann. "Merging a Culture of Writing with a Culture of Assessment: Embedded, Discipline-based Writing Assessment." Assessment in Writing. Ed. Marie C. Paretti and Katrina Powell. Assessment in the Disciplines Series, Volume 4. Tallahassee: Association of Institutional Research, 2009. 49-64. Print.

Zawacki, Terry Myers, E. Shelley Reid, Ying Zhou, and Sarah E. Baker. "Voices at the Table: Balancing the Needs and Wants of Program Stakeholders to Design a Value-Added Writing Assessment Plan." [Special issue on Writing Across the Curriculum and Assessment] Across the Disciplines 6 (December, 2009). Web. 11 July 2013. 